Case Report

\title{
De Novo Trisomy 1q10q23.3 Mosaicism Causes Microcephaly, Severe Developmental Delay, and Facial Dysmorphic Features but No Cardiac Anomalies
}

\author{
Shirley Lo-A-Njoe, ${ }^{1}$ Lars T. van der Veken, ${ }^{2}$ Clementien Vermont, ${ }^{1}$ Louise Rafael-Croes, \\ Vincent Keizer, ${ }^{1}$ Ron Hochstenbach, ${ }^{2}$ Nine Knoers, ${ }^{2}$ and Mieke M. van Haelst ${ }^{2}$ \\ ${ }^{1}$ Department of Pediatrics, Horacio Oduber Hospital, Oranjestad, Aruba \\ ${ }^{2}$ Department of Genetics, Wilhelmina Children's Hospital, UMC Utrecht, 3584 EA Utrecht, Netherlands
}

Correspondence should be addressed to Shirley Lo-A-Njoe; smloanjoe@yahoo.com

Received 12 November 2015; Accepted 6 January 2016

Academic Editor: Philip D. Cotter

Copyright (C) 2016 Shirley Lo-A-Njoe et al. This is an open access article distributed under the Creative Commons Attribution License, which permits unrestricted use, distribution, and reproduction in any medium, provided the original work is properly cited.

Proximal duplications of chromosome 1q are rare chromosomal abnormalities. Most patients with this condition present with neurological, urogenital, and congenital heart disease and short life expectancy. Mosaicism for trisomy lq10q23.3 has only been reported once in the literature. Here we discuss a second case: a girl with a postnatal diagnosis of a de novo pure mosaic trisomy 1q1023.3 who has no urogenital or cardiac anomalies.

\section{Introduction}

Proximal duplications of chromosome lq are rare chromosomal abnormalities. Affected patients present with neurological, urogenital, and congenital heart anomalies as reported by Chen et al. [1], Mertens et al. [2], Machlitt et al. [3], Patel et al. [4], and Sifakis et al. [5]. Mosaicism for 1q10q23.3 duplication has only been reported once by Hirshfeld et al. [6]. Here, we report a second case with a postnatal diagnosis of a de novo pure mosaic trisomy 1q10q23.3. Although the girl has a developmental delay and similar facial dysmorphism as the previous reported case, she has no cardiac or urogenital anomalies. The absence of cardiac and urogenital anomalies is of importance for prognosis and illustrates the importance of (prenatal) counseling of parents of patients with trisomy lq10q23.3 mosaicism.

\section{Case Report}

The proband was the first child of healthy unrelated Caribbean parents. She was born after a term pregnancy with a birth weight of $3120 \mathrm{~g}$. The mother was 19 years old and the father was 22 years old at time of delivery. Apart from her father's sickle cell disease (HbSC), family history is noncontributory. Pregnancy care was performed by a midwife. Because of the uncomplicated pregnancy and the fact that Aruba does not yet have standardized 20-week fetal screening, no additional fetal testing (fetal ultrasound or prenatal genetic testing) was performed. The neonatal period was uncomplicated. At nine months of age she was referred to the pediatrician for evaluation of developmental delay. At that time she had a variable head lag and could not turn or sit independently. Feeding was uneventful and no illnesses, medication, or admissions were noted. On clinical examination, length was $71 \mathrm{~cm}$ (75th percentile), weight was $7650 \mathrm{~g}$ (10th percentile), and head circumference was $42 \mathrm{~cm}$ $(<3$ th percentile). She was microcephalic and had a metopic ridge, small palpebral fissures with epicanthic folds, two naevi on the right side of the face, a wide depressed nasal bridge, a full and long philtrum, retrognathia, creases in the earlobes, a narrow palate, full cheeks, dimples on both elbows, rocker bottom feet, hemangioma on left hallux, and a sacral dimple (Figure 1). Neurological examination revealed axial hypotonia and variable head lag. Additional testing was 


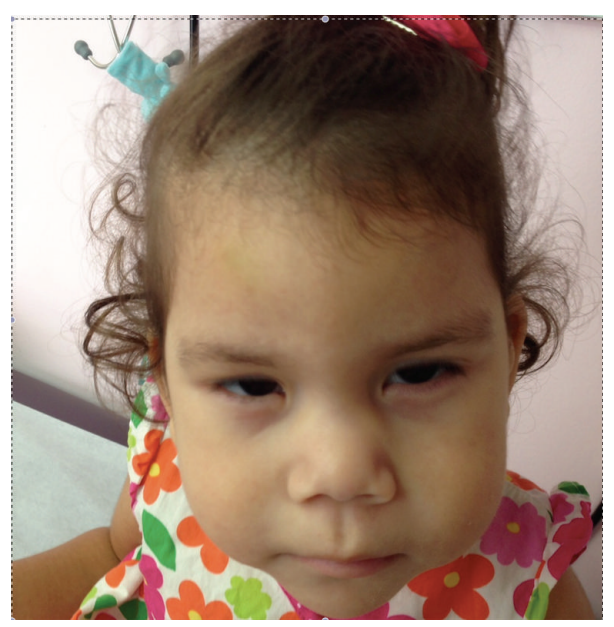

FIGURE 1: Face: note microcephaly; metopic ridge; wide, depressed nasal bridge; long philtrum; full cheeks; and retrognathia.

performed from June 2013 till June 2014. Echocardiography showed a structural and functional normal heart, with a normal aortic arch; there were no signs of (hypertrophic) cardiomyopathy. Electrocardiography showed a normal sinus rhythm, sinus arrhythmia, no preexcitation, and no signs of ventricle hypertrophy, a normal conduction and repolarization. A CT of the brain showed a normal aspect of corpus callosum and normal basal ganglia, and there were no calcifications. MRI of the brain showed subendymal heterotopia towards the right lateral ventricle, without other abnormalities. Sonography of the kidneys showed normal kidneys and urinary tract. Ultrasound of the spine suggested spina bifida; however, MRI of the spine showed only lumbarization of S1 without signs of spina bifida.

Biochemical investigations in blood showed, apart from HbSC, no hematologic, renal, or liver function abnormalities. Cytogenetic analyses on blood lymphocytes showed a mosaic duplication of arm of chromosome 1q10 to 1q23.3. Because the proband was delivered by a midwife after an uneventful pregnancy and delivery she was not seen by a physician, as such no testing was performed at birth of child or placenta. Parental karyotypes were normal.

SNP-array analysis showed a female array profile suggestive of a mosaic copy number gain of $\sim 18.0 \mathrm{Mb}$ in chromosomal region 1q21.1q23.3 (8141 probes) (Figure 2): ISCN 2013 nomenclature, ISCN [7]: arr[hg19] 1q21.1q23.3(144,854,574$162,843,606) \times 2 \sim 3$.

Routine karyotyping confirmed the mosaic copy number gain as suspected by the SNP-array investigation. A supernumerary derivative of chromosome 1 was detected in 4 out of 16 metaphases; analyzing the remaining metaphases showed a normal female karyotype. The derivative consisted of the proximal part of the long arm of chromosome 1 from the centromere to the breakpoint in band 1q23.3 (Figure 3). Followup investigation in both parents indicated that the duplication arose de novo. The parental origin of the duplicated region was not investigated. The mosaic nature of the duplication probably indicates that the duplication was generated during one of the early postzygotic mitoses.
Thus far there is only one case reported in the literature with mosaicism for overlapping partial trisomy lq duplication Hirshfeld et al. [6]. This previously reported patient had similar facial dysmorphic features to the present patient (Figure 1). In addition, she had mild bilateral hydronephrosis and hypertrophic cardiomyopathy with left ventricular outflow tract obstruction and Wolff-Parkinson-White syndrome.

Other presented cases with proximal trisomy 1q duplications presented with a wide range of neurological, urogenital, and congenital heart anomalies (Table 1). The authors hypothesize that the cardiac anomalies could be caused by a disruption or increased dosage effect of TPM3 which is located within the duplicated region. Since cardiac anomalies are absent in the present case and her duplicated chromosomal region harbors (apart from LMXA1) the same genes, it is less likely that TPM3 is a candidate gene for dilated and hypertrophic cardiomyopathy. The cardiac phenotype could thus result from mutations in other sarcomeric genes. The percentage of mosaicism for 1q10q23.3 duplication in the heart can however not be predicted from the performed analysis in blood and could completely differ between the present and previously reported case, possibly explaining the absence of cardiac anomalies in our case. An increased dosage effect of candidate gene TPM3 could then still result in congenital heart disease in the previous case. Although we did not reveal cardiac abnormalities at the age of 1 year in the present case, a spontaneous closed foramen ovale or patent ductus arteriosus or transient hypertrophy in our case cannot be fully excluded. As yet, no rhythm or conduction disturbances have been noted, but follow-up will occur yearly.

In conclusion, this report suggests that congenital heart disease and urogenital abnormalities are no clear diagnostic features of mosaic trisomy 1q10q23.3. However, as with all mosaic chromosomal anomalies, the severity of affected organs is difficult to predict as it depends on the percentage of mosaicism of the chromosomal abnormality in the specific organ systems. Careful genetic counseling is warranted in case of (prenatal) detection of pure de novo trisomy 1q10q23.3 duplication as well as regular cardiac follow-up screening for 


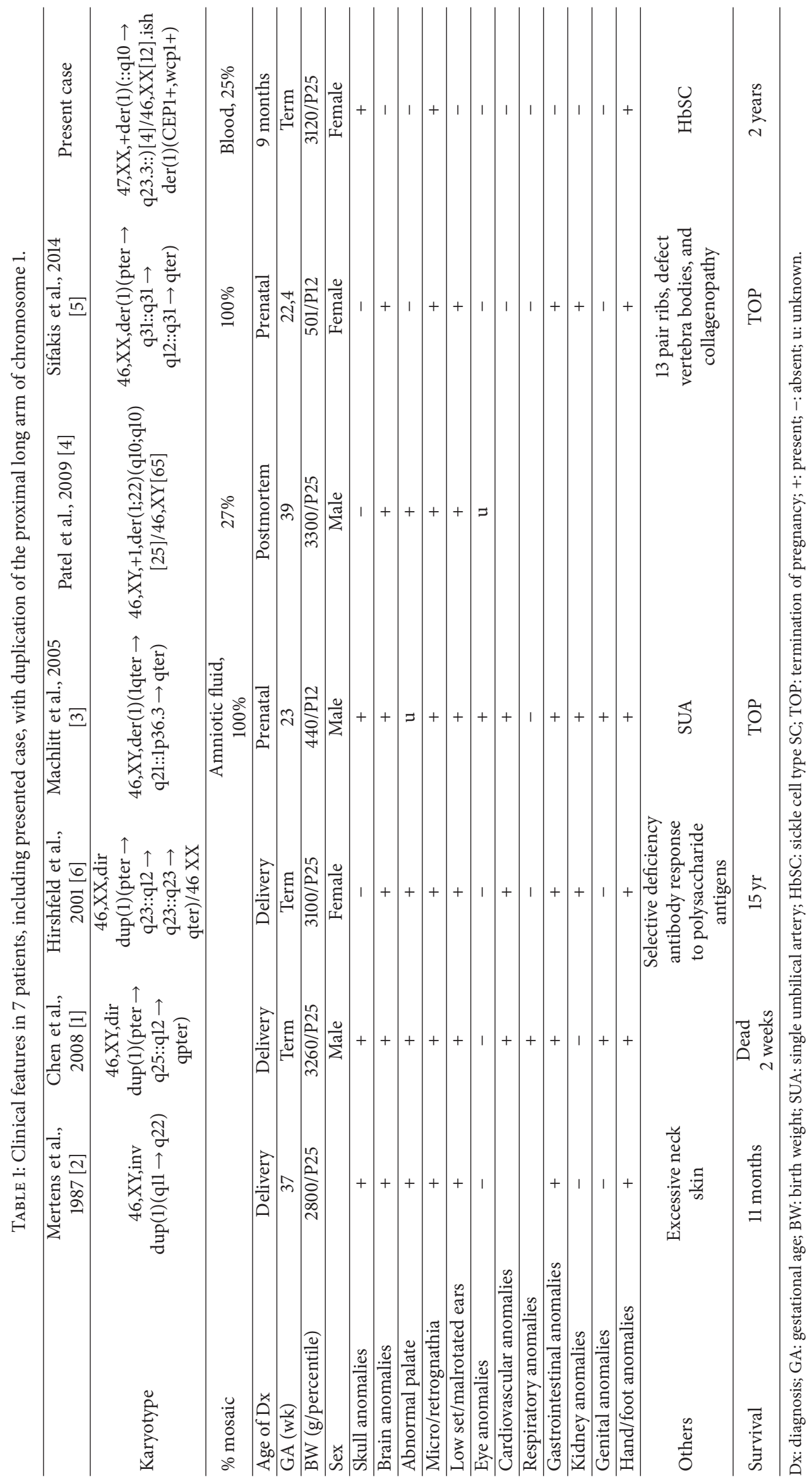




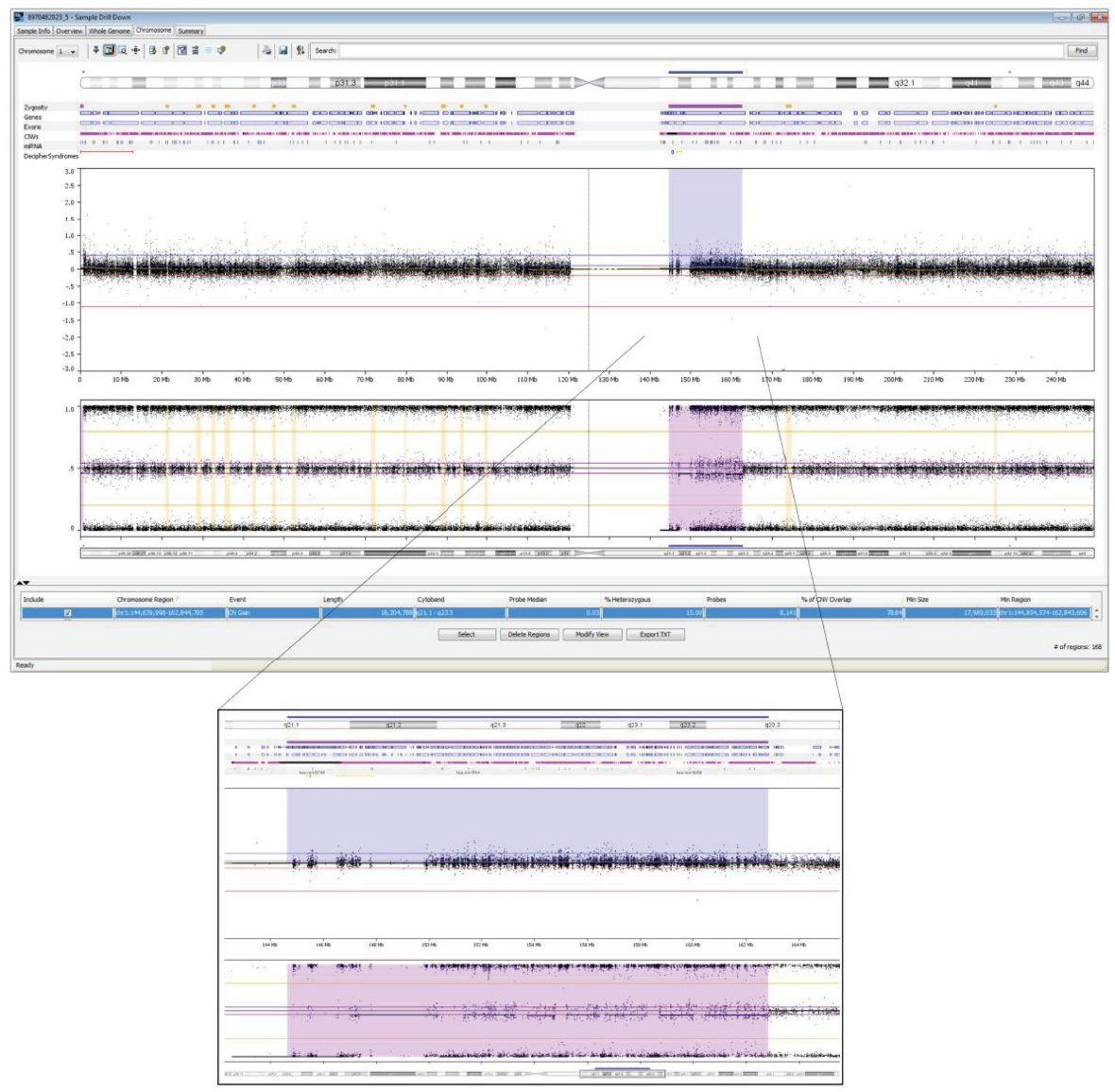

FiguRE 2: SNP-array analysis showed a mosaic duplication of $\sim 18.0 \mathrm{Mb}$ in 1q21.1-1q23.3: arr[hg19] 1q21.1q23.3(144,854,574-162,843,606) $\times 2$ 3. The upper $y$-axis shows the $\log 2 \mathrm{R}$ ratio and the lower $y$-axis indicates the $\mathrm{B}$ allele frequency.

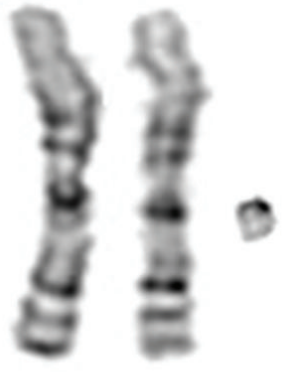

(a)

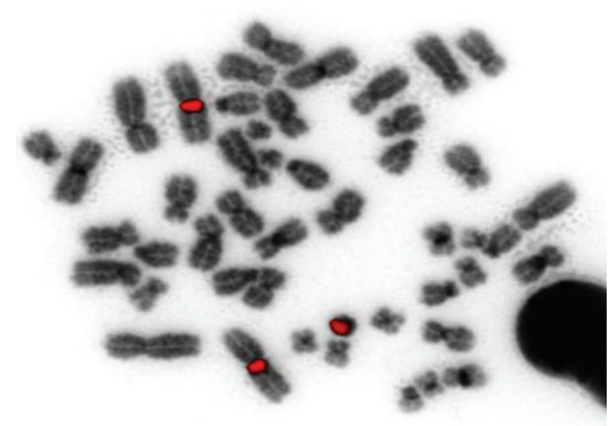

(b)

FIGURE 3: Partial G-banded karyogram showing both normal chromosomes 1 and the supernumerary der(1)(:q10 $\rightarrow$ q23.3:) (a) and a metaphase after FISH using a satellite III DNA-probe (Vysis) showing three signals on band 1q12 (b).

similar cases without cardiac anomalies. Since this is only the second report of a mosaic trisomy 1q10q23.3, further cases need to be reported to further delineate the associated phenotype.

\section{Conflict of Interests}

The authors declare that there is no conflict of interests regarding the publication of this paper. 


\section{References}

[1] C.-P. Chen, Y.-J. Chen, S.-R. Chern et al., "Prenatal diagnosis of mosaic 1q31.3q32.1 trisomy associated with occipital encephalocele," Prenatal Diagnosis, vol. 28, no. 9, pp. 865-867, 2008.

[2] F. Mertens, B. Johansson, M. Forslund, M. Olsson, and U. Kristoffersson, "Tandem duplication (1) (q11 $\rightarrow$ q22) in a male infant with multiple congenital malformations," Clinical Genetics, vol. 32, no. 1, pp. 46-48, 1987.

[3] A. Machlitt, P. Kuepferling, C. Bommer, H. Koerner, and R. Chaoui, "Prenatal diagnosis of trisomy 1q21-qter: case report and review of literature," American Journal of Medical Genetics Part A, vol. 134, no. 2, pp. 207-211, 2005.

[4] C. Patel, G. Hardy, P. Cox, S. Bowdin, C. McKeown, and A. B. Russell, "Mosaic trisomy 1q: the longest surviving case," American Journal of Medical Genetics Part A, vol. 149, no. 8, pp. 1795-1800, 2009.

[5] S. Sifakis, M. Eleftheriades, D. Kappou et al., "Prenatal diagnosis of proximal partial trisomy 1q confirmed by comparative genomic hybridization array: molecular cytogenetic analysis, fetal pathology and review of the literature," Birth Defects Research Part A-Clinical and Molecular Teratology, vol. 100, no. 4, pp. 284-293, 2014.

[6] A. B. Hirshfeld, W. Reid Thompson, A. Patel, L. B. Boone, and A. M. Murphy, "Proximal trisomy of 1q mosaicism in a girl with hypertrophic cardiomyopathy associated with WolffParkinson-White syndrome and multiple congenital anomalies," American Journal of Medical Genetics, vol. 100, no. 4, pp. 264-268, 2001.

[7] ISCN, An International System for Human Cytogenetic Nomenclature, edited by L. G. Shaffer, J. McGowan-Jordan and M. Schmid, S. Karger, Basel, Switzerland, 2013. 


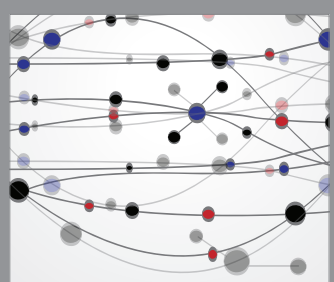

The Scientific World Journal
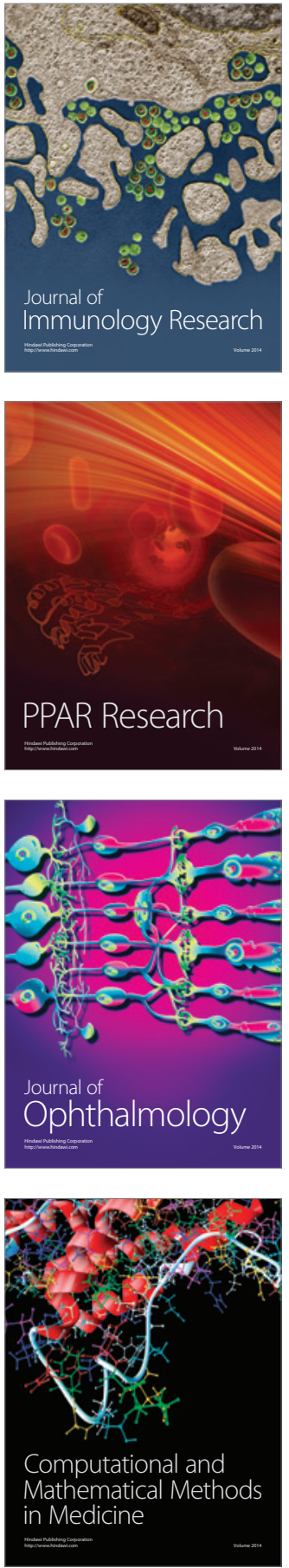

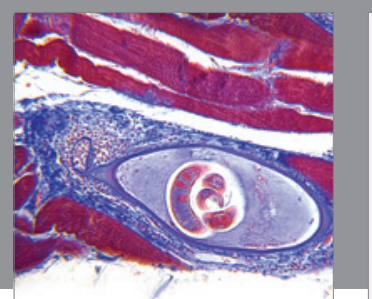

Gastroenterology Research and Practice

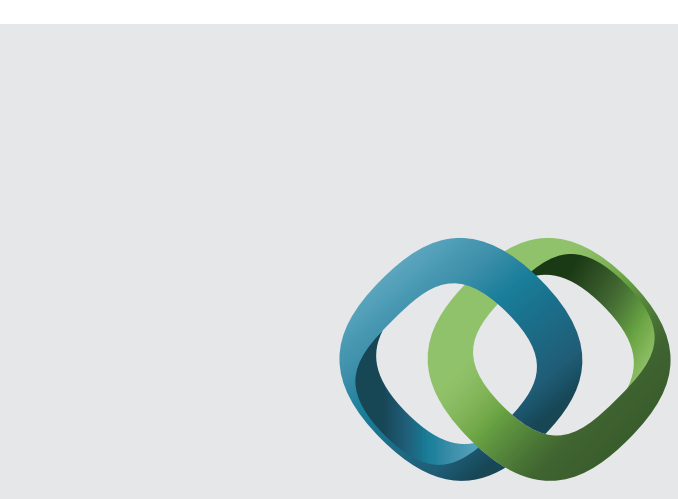

\section{Hindawi}

Submit your manuscripts at

http://www.hindawi.com
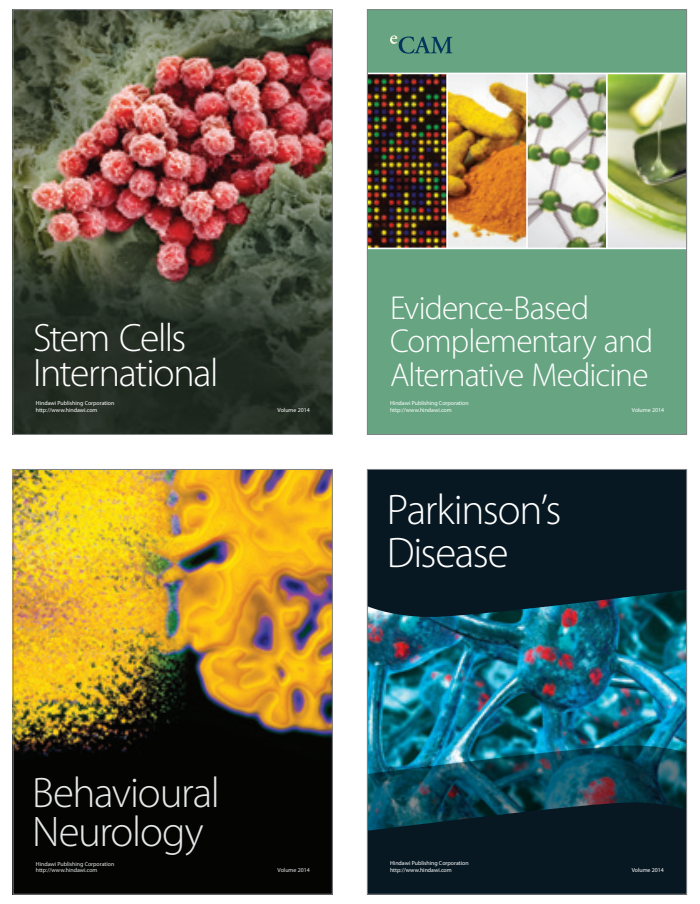
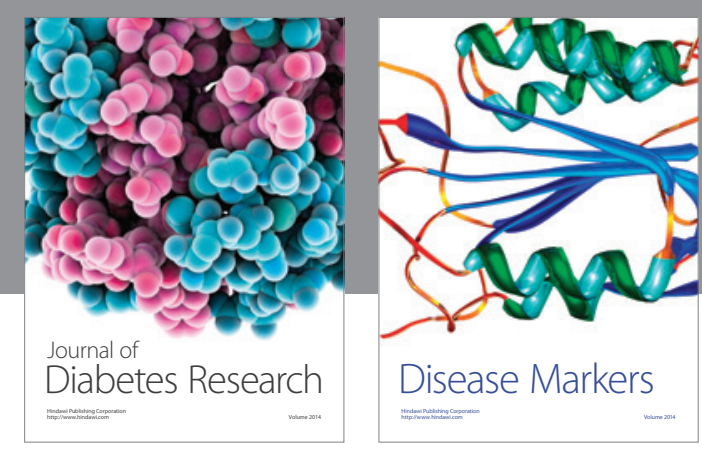

Disease Markers
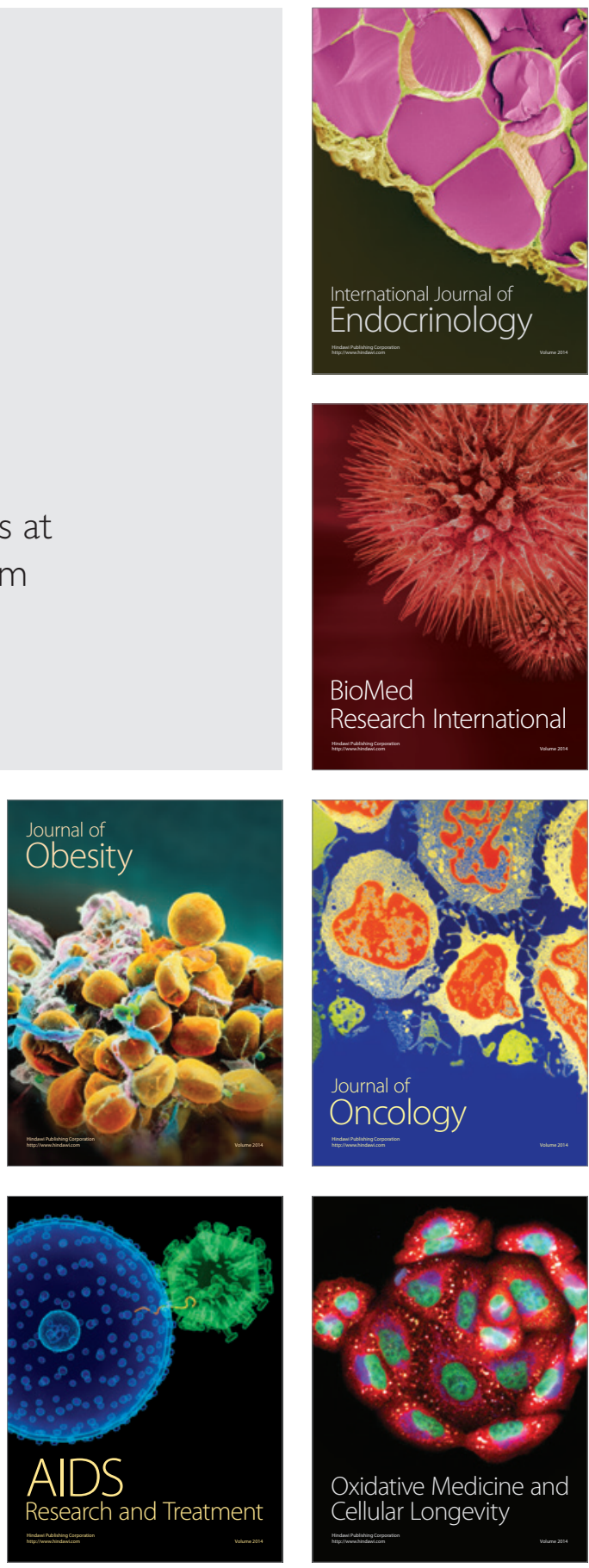